\title{
Monitoring and Evaluation: A Key to Effective and Efficient Education Delivery at College of Education, Azare, Bauchi State
}

\author{
Zuwaira A. Abdullahi \\ School of Education, College of Education, Azare, Bauchi State
}

\author{
Doi:10.5901/jesr.2014.v4n7p133
}

\begin{abstract}
Monitoring and evaluation of projects and programs are increasingly becoming on indispensable management tools because they area a pre-requisite in the design and implementation of plans as well as a feedback mechanism and a means of controlling activities that are essentially concern with measuring progress and correcting deviations. In Nigeria, there is a relatively law level of achievement and standard at school level due to gabs in monitoring and evaluation of teachers instructional task performance/curriculum delivery by concern authorities. This paper therefore stressed the importance of Monitoring and Evaluation towards providing effective and efficient Education Delivery at College of Education, Azare-Bauchi State. The population of the study therefore consisted of all management officers, officers of project monitoring unit (PMU), Lecturer and Student of the college. A total number of 120 respondents were drawn out of the population to represent the whole using stratified random sampling technique to collect data for the study. A self designed questionnaire was developed, validated and applied on the sample for the study. It has been observed that productive teaching of all courses at COE Azare was all part of effective monitoring and evaluation. It is therefore against this background that appropriate recommendation(s) were proffered.
\end{abstract}

\section{Introduction}

Monitoring and Evaluation of projects and programs are increasingly becoming an indispensable management tools because they are a feedback mechanism and a means of controlling activities that are essentially concern with measuring progress and correcting deviation.

Education which is an agent of social change that fosters the development of man and society (Audu 2003) is an important medium for economic growth, social harmony and political stability. Hence, every society or organization has its own unique way and pattern of providing educational services to its members.

At COE Azare - Bauchi State, educational programs are designed to integrate individual learners into sound and effective citizens. And for this to be done, the COE Azare established a Project Monitoring Unit (PMU) under the Directorate of Administrative Planning and Quality Control to constantly monitor and evaluate the education programs and delivery. These are no ordinary exercise but an essential professional component of ensuring orientation towards goals achievement (Azare 2002). Therefore, monitoring and evaluation as a key to effective and efficient education delivery at COE Azare, is to build a system of setting quality standard, measuring performance against the set standard and taking appropriate action to deal with deviations outside permitted tolerance.

\subsection{Literature review}

Monitoring and Evaluation is not only a systematic investigation of a plan or process implementation using appropriate tools with a view of achieving an objective understanding of the plan or process and if necessary proffer solutions; but it is a means to regulate and control with the aim of achieving the established targets. Hence, monitoring involves observation and checking with the view to arriving at a meaningful conclusion while Evaluation is the judgment of merit (Ebel 1972) for worth while results.

Apart from the issue of proper funding, the most apparent challenge in the effective and efficient education delivery is in the area of monitoring and evaluation which is basically a system of setting quality standard, measuring performance against such standards and taking appropriate action to correct deviation outside permitted tolerance (Gerald Cole 2004). Monitoring and Evaluation have been in existence as an integral part formal education system in Nigeria (Fafunwa $A B$ 2002). It has tended to maintain the same purpose: the purpose of control, identification of areas where remedial action is needed and bringing about effective learning environment irrespective of the effects of the various historical 
developments that have effect education over the years.

\subsection{Objectives}

The main objectives of this research paper are:

i. To identify the set objectives and targets meant to be achieve by the Project Monitoring Unit (PMU) of the Directorate of the Administrative Planning and Quality Control (DAP\&QC) and how does these objectives and target impact on the education delivery at COE Azare.

ii. To identify the require mechanism put in place for Quality Assurance and Quality Control (QAQC) procedure to sustain the effective and efficient education delivery at the college of education, Azare.

iii. To find out whether there is (and how effective is ) an established Data bank ( for information and statistics) about teacher effectiveness, the need of the college (infrastructure, funding etc) and the problems that may hinder of the achievement of set targets.

\subsection{Research questions}

The study aims at answering the following research questions:

i. What are the objectives and targets of the P.M.U and how does it impact in the educational delivery at COE Azare?

ii. Are there an established data bank(for information and statistics) about teacher effectiveness, and the problem that may likely hinder the attainment of set targets.

iii. Are the require mechanism put in place for a QAQC procedure to sustain the effective and efficient education delivery at COE Azare?

\section{Research Design and Methodology}

The study is a descriptive survey carried out through focus group discussion, observation and distribution of questionnaires to sample subjects. Data collection, collation and analysis were done using the descriptive survey method which permitted a researcher to study small sample and then generalized the findings to whole population (Osuala 1985).

\subsection{Population of the study}

The population is 1,214 subjects comparing Management and staff PMU (73), Academic staff/lecturers (352) and Students (789) as show in table (2.1) below:

\begin{tabular}{|c|c|c|}
\hline S/No & Categories & Population \\
\hline 1 & Mgt staff and PMU staff & 73 \\
\hline 2 & Academic staff/lecturers & 352 \\
\hline 3 & Students & 789 \\
\hline & total & 1214 \\
\hline
\end{tabular}

Source: Zuwaira, AA. Field work (2014).

\subsection{Sample and sampling technique}

Considering the size of the population for the study, collecting information needed for this study require direct communication with all of them which may not be possible even if resource are not limited. Hence, a carefully chosen sample has been selected to provide information about the whole (Osuala 1985). This is necessary to safe guard the survey and makes it free from bias.

Proportionate stratified random sending was used in selecting the sample for this study because the population has been categorized into different strata. It is proportional because the number in the sample from the three distinct categories (Mgt \& PMU staff, Academic staff and Students) is proportional to their actual population and each is selected at random to ensure that every one has an equal chance of being selected. The sample selected for this study are 15 Management/PMU staffs, 45 Academic staffs and 78 Students as shown in table 2.2 below. 


\begin{tabular}{|c|l|c|c|}
\hline S/N & Category & Population & Sample \\
\hline 1 & Mgt- Pmu Staffs & 73 & 7 \\
\hline 2 & Academic Staffs & 352 & 35 \\
\hline 3 & Students & 789 & 78 \\
\hline & Total & 1,214 & 120 \\
\hline
\end{tabular}

Source: Zuwiara AA. Field work 2014.

\subsection{Instrument for data collection}

Data has been objectively collected using Oral discussion/interviews and Questionnaire. However the bulk of the information come from the questionnaire administered to the randomly selected 120 respondents. The questionnaire was intended to among others give the respondents the chance to asses the impact of monitoring and evaluation as a key to effective and efficient education delivery at COE AZARE

\subsection{Validity and reliability of data collection instrument}

The instrument was validated by experts who have at least adecade of cognate experience in the teaching and research at the COE AZARE.

For the reliability of the instruments, a pilot study was conducted on a small portion of the sample population (at least 2 PMU staffs, 3 Academic staffs and 7 Students) two weeks before the actual survey. Thus, the scores of the $1^{\text {st }}$ and $2^{\text {nd }}$ questionnaire administration were computed and correlated using a Pearson product moment correlation statistical tool. A score of 0.67 was attained which is on indication of a positive correlation.

\subsection{Data analysis procedure}

Data collected and collated from the administered questionnaire were analyzed in numerical terms and simple percentage for easy comprehension of the corresponding relationship of the issue at stake.

\section{Data Presentation and Result}

The following data were obtained for objective appraisal and analysis in an attempt to one answer to the research questions, thus;

3.1 The objectives of the Project Monitoring Unit (PMU) of the Direction Administrative Planning and Quality Control and how does the objective impact on education delivery at the COE Azare.

Table 3.1 below shows the response obtained in trying to education delivery at the COE Azare.

Table 3.1 below shows the response obtained in trying to find out the answer to research question 1.

\begin{tabular}{|c|c|c|c|c|}
\hline S/No & Questions & Yes & No & Undecided \\
\hline $\mathrm{a}$ & Are you aware of the existence of PMU and its QAQC procedure? & $93 / 77 \%$ & $25 / 21 \%$ & $2 / 2 \%$ \\
\hline $\mathrm{b}$ & Do the QAQC procedures impact positively on Educational delivery at COE Azare? & $16 / 13 \%$ & $17 / 14 \%$ & $5 / 4 \%$ \\
\hline C & Are the teaching/learning strategies of COE Azare in harmony with the set targets of the PMU & $88 / 73 \%$ & $16 / 13 \%$ & $17 / 14 \%$ \\
\hline
\end{tabular}

Source: Zuwaira AA field survey 2014.

From the table above, it can be seen that majority of the respondents (77\%) are not only aware of the existence of P.M.U and its QAQC procedure but $83 \%$ of them are of the opinion that the QAQC procedure do impact positively on the education delivery at COE Azare. $73 \%$ of the respondents also opined that teaching and learning strategies at COE Azare are in harmony with the QAQC set targets.

Therefore, the overall result form the table above indicates that the objectives and QAQC targets of the PMU at COE Azare impact on the effective and efficient education delivery. 
3.2 Established Data Bank (for information and statistics) about teacher effectiveness and the problems that may hinder the attainment of set QAQC targets.

Table 3.2 below indicates the responses obtained in trying to answer the research question number two, thus

\begin{tabular}{|c|l|c|c|c|}
\hline S/No. & Questions & Yes & No & Undecided \\
\hline a & $\begin{array}{l}\text { Do the college management provide the enabling environment for effective and efficient } \\
\text { education delivery }\end{array}$ & $90 / 75 \%$ & $18 / 15 \%$ & $12 / 10 \%$ \\
\hline b & Are teachers very effective in the discharge of their duties and responsibilities & $109 / 91 \%$ & $8 / 7 \%$ & $3 / 2 \%$ \\
\hline c & $\begin{array}{l}\text { Is there a feedback mechanism for purposeful constructive advice on how to improve the } \\
\text { quality of education delivery at COE Azare }\end{array}$ & $78 / 65 \%$ & $36 / 30 \%$ & $6 / 5 \%$ \\
\hline
\end{tabular}

Source: Zuwaira AA. Field survey 2014.

From the above table it can be deduced that $70 \%$ of the respondents are of the opinion that the management at $\mathrm{COE}$ Azare does provide the enabling environment for effective and efficient education delivery as against the $15 \%$ who hold a country opinion and another $10 \%$ that remain undecided. Also, a vast majority $91 \%$ are of the opinion that apart from having the enabling environment, teachers at COE Azare are very effective in the discharge of their duties. In addition to this, $65 \%$ of the respondents agree with the assertion that there is a feed back mechanism (which needs to be improving upon) for purposeful and constructive advice to improve on the quality of education delivery at COE Azare.

Based on the opinions expressed, respondents support the assertion that there is an established data bank about teacher effectiveness and the problems that may likely hinder the attainments of set QAQC targets; an opinion that affirmatively support the fact that monitoring and evaluation is a key to effective and efficient education delivery at COE Azare.

\subsection{The Required mechanism for a QAQC procedure to sustain the effective and efficient education delivery.}

Table 3.3 below shows the opinion(s) of the respondents in answering the research question number 3

\begin{tabular}{|c|l|c|c|c|}
\hline S/n & Question & Yes & No & Undecided \\
\hline a & $\begin{array}{l}\text { Are the problems encountered in measuring performance against standard being } \\
\text { adequately identified and addressed? }\end{array}$ & $84 / 70 \%$ & $22 / 18 \%$ & $14 / 12 \%$ \\
\hline b & Are the QAQC procedures and targets set sustainable? & $88 / 73 \%$ & $25 / 21 \%$ & $7 / 6 \%$ \\
\hline
\end{tabular}

Source: Zawaira AA. Field survey 2014.

In trying to find the answer to research question $3,70 \%$ of the respondent agreed that problems that usually come up in the course of routine monitoring and evaluation and or QAQC procedure for measuring performance against standard are carefully and adequately identified and addressed. Another set of respondents (73\%) also opined that the QAQC procedure put in place by the PMU to effectively and efficiently monitor and evaluate education delivery at COE Azare is sustainable.

\section{Discussion of Finding and Result}

Following the administrative of the questionnaire and the responses obtained these from, the data have revealed a lot on how monitoring and evaluation and or the QAQC procedure put in place by the PMU at COE Azare will, for a long time to come, remain a vital key to effective and efficient education delivery. This is in line with the opinions put forward by Mdoh, Bako, Akenidayo and Yusuf (1993) that monitoring and evaluation is identified as an important management function necessary for ensuring effective and efficient service delivery.

The responses to questions $3.1 \mathrm{a}, \mathrm{b} \& \mathrm{c}$ of the questionnaire (table3.1) clearly indicate that the PMU have done excellently well not only in making sure that all stakeholders at COE Azare are aware of its existence, functions, challenges and prospects but their routine monitoring and evaluation exercise are in harmony with teaching and learning strategies which ultimately impacted positively on education delivery. This underscore the importance of regular monitoring and evaluation exercise as a means of checking the extent to which targets are set, the mean and process of 
achieving the set target as well as attainment of such targets remain on course and according to plans.

The responses to questions $3.2 \mathrm{a}, \mathrm{b} \& \mathrm{c}$ of the questionnaire (table 3.2 ) clearly indicates that in as so far as monitoring and evaluation will remain a key for effective and efficient education delivery at COE Azare, the enabling environment provided by the college management as agreed by $75 \%$ of the respondents, the existing feedback mechanism in place for purposeful and constructive advice as agreed by the $65 \%$ of the respondents and as well as the high level of efficiency and effectiveness exhibited by the teachers as agreed by the $91 \%$ of the respondents have to remain intact or possibly improve upon.

In addition, some respondents (70\%) are of the opinion that in measuring performance against standard, all problems encountered are realistically addressed to identify areas of strength and or weakness with the view of providing a clear and accurate record so that they are incorporated in to the on going planning.

$73 \%$ of the respondents (table 3.3) opined that the QAQC procedure put in a place by the PMU to ensure effective and efficient education delivery at $\mathrm{COE}$ Azare through periodic and regular monitoring and evaluation are quite sustainable

From the foregoing, it can be deduced that the only way to guarantee effective and efficient education delivery at COE Azare is for the PMU to ensure regular monitoring and evaluation of learning activities which is a continuous process and a function that uses the systematic collection of data on specified indicators as well as periodic objective assessment which provide the stakeholders with the indication of the extent of progress and achievement of output and outcome.

\subsection{Conclusion}

Unless COE Azare is a just a place where teachers and learners go merely to chalk up attendance records, concern for effective and efficient education delivery must also take into cognizance performance and the quality of what is learnt. It is only if all the parameters of effective management are in place that quality assurance and quality control (QAQC) can be achieved. For effective and efficient education delivery, the COE Azare should be well organized so that learning can take place in a conducive atmosphere and enabling environment. Hence a proactive management style from the authorities concern is required in which the input variables, the process variables and well as the output variables can be check and re-asses from time to time.

\subsection{Recommendation}

Resources (financial, material time etc), training opportunities, improve welfare packages, modern facilities and equipment etc have to be periodically monitored and evaluated to ensure orientation towards goal achievement. Beside, the result of the periodic monitoring and evaluation exercises have to be implemented since the challenge for a sustainable strategy and innovation that can enable the PMU and the stakeholders to work towards effective and efficient education is a continuous process. Therefore, there is a need for partnership and synergy among and between the stakeholders at COE Azare for monitoring and evaluation to remain a key in the effective and efficient education delivery.

\section{References}

Azare GD(2000) Basic concerns. Revitalizing Nigerian Primary Education in the new millennium .A Professional inaugural lecture. BUK. An introduction to Result-Based Monitoring and Evaluation (2007). Proceedings of a workshop organized by Book aid international Abuja. Nigeria.

Eden DA (1984) Introduction to Education Administration in Nigeria. Lagos-Nigeria Macmillan Nigeria Publishers Ltd. Fafunwa AB (2002) History of Nigeria Education, Ibadan. NPS Education Publishers Ltd. Omale AA, Gbery AJ, Adewale ed. (2004) "Issue in Education measurement and evaluation in Nigeria. (in Honour of Wole Folayayo) Osuala (1985) Introduction to Research Methodology. Onitsha .Africa Fab. Publishers.

Sambo AA (2005) Research Methods in Education. Ibadan. Stir line-Harden Publishers Nig https://www.globalpartnership.org/ How we measure success.

https://www.sic.org/ education/monitoring and evaluation literacy and education programs. 